\title{
Gorlin's syndrome: An interesting case study and literature review
}

\author{
Robyn J Watts MD, Justin Paletz MD FRCSC
}

RJ Watts, J Paletz. Gorlin's syndrome: An interesting case study and literature review. Can J Plast Surg 2004;12(2):76-78.

Gorlin's syndrome, or basal cell nevus syndrome, is a relatively rare disease. It consists of a classic pentad of features comprised of multiple basal cell carcinomas, jaw cysts, calcification of the falx cerebri, pitting of the palmar and plantar surfaces and rib anomalies. A review of the clinical features, differential diagnosis, clinical work-up and current treatment is presented.

Key Words: Basal cell carcinoma; Basal cell nevus syndrome; Gorlin-Goltz syndrome; Gorlin's syndrome; Nevoid basal cell carcinoma syndrome

\section{Syndrome de Gorlin : étude de cas intéressant et examen de la documentation}

Le syndrome de Gorlin, ou naevomatose baso-cellulaire, est une maladie relativement rare. Il comprend cinq manifestations classiques, soit la présence de multiples carcinomes baso-cellulaires, de kystes maxillaires, de dépôts calcaires dans la faux du cerveau, de porokératose palmoplantaire et d'anomalies costales. Nous passerons en revue, dans le présent article, les manifestations cliniques, le diagnostic différentiel, l'exploration clinique et le traitement actuel du syndrome.

\section{History}

A case of a 60-year-old man who was employed as a coast guard for many years is presented. Since his twenties, he has had hundreds of basal cell carcinomas (BCC) removed from his face, back and hands. There was no history of acute burns, although he has had extensive sun exposure from working at sea. He denied having any other skin disorders. He was otherwise healthy, apart from moderate hypertension that was well controlled with Vasotec (Merck Frosst, Canada). He had a cyst excised from his mandible with subsequent rib graft reconstruction and excision of two epidermal cysts: one from his left thumb and the other from his left ring finger. There was no similar history of skin cancers among his family members and he had no children of his own. He was an exsmoker and he had no known drug allergies. The review of systems was otherwise noncontributory. Past medical treatment of the multiple BCC included the use of cryotherapy for superficial lesions, the application of topical 5-flourouracil (Efudex, ICN, Canada) along with electrodessication and curettage for moderate lesions. For deeper lesions, he was followed closely by plastic surgery. He underwent many excisions that were closed primarily by local skin flap, split thickness skin graft or full thickness skin graft.

\section{Physical examination}

Head and neck examination revealed slight hypertelorism. No lymphadenopathy was evident. The dermatological examination demonstrated multiple erythematous scaly and pearly nodular lesions on the scalp, face (Figure 1), trunk, back and hands, and an epidermal cyst behind the ear. Further examination of the skin revealed pitting of the palms, soles and volar aspects of the fingers. Also, there was a significant number of scars related to many previous excisions. Cardiovascular, respiratory, gastrointestinal and neurological exams were unremarkable.

\section{Investigations}

Blood work showed normal electrolytes and complete blood count. His cholesterol was elevated at $6.8 \mathrm{mmol} / \mathrm{L}$. Chest $\mathrm{x}$-ray demonstrated the presence of bifid ribs. Computed tomography of the head revealed calcification of the falx cerebri.

\section{REVIEW OF LITERATURE}

Gorlin's syndrome is also referred to as basal cell nevus syndrome, Gorlin-Goltz syndrome and nevoid basal cell carcinoma syndrome. It is a genetic disease transmitted in an autosomal dominant fashion with complete penetrance and variable expression. However, $35 \%$ to $50 \%$ of cases result from spontaneous mutation and, therefore, occur in the absence of family history. Previously mapped to chromosome 9, the involved gene is a tumour suppressor gene that when mutated, becomes inactive allowing basal cell malignancies to proliferate (1). Documented prevalence ranges anywhere from one in 57,000 to one in 164,000 people (2). Over 100 characteristics have been associated with Gorlin's syndrome. Fortunately, the majority of these features are clinically silent. The classic pentad is comprised of multiple BCCs, jaw cysts, calcification

Division of Plastic Surgery, New Halifax Infirmary, Dalhousie University, Queen Elizabeth II Health Science Centre, Halifax, Nova Scotia Correspondence: Dr Robyn Watts, 1862 Vernon Street, Halifax, Nova Scotia B3H 3N7. Telephone 902-446-4285,

e-mail rwattsy@hotmail.com 


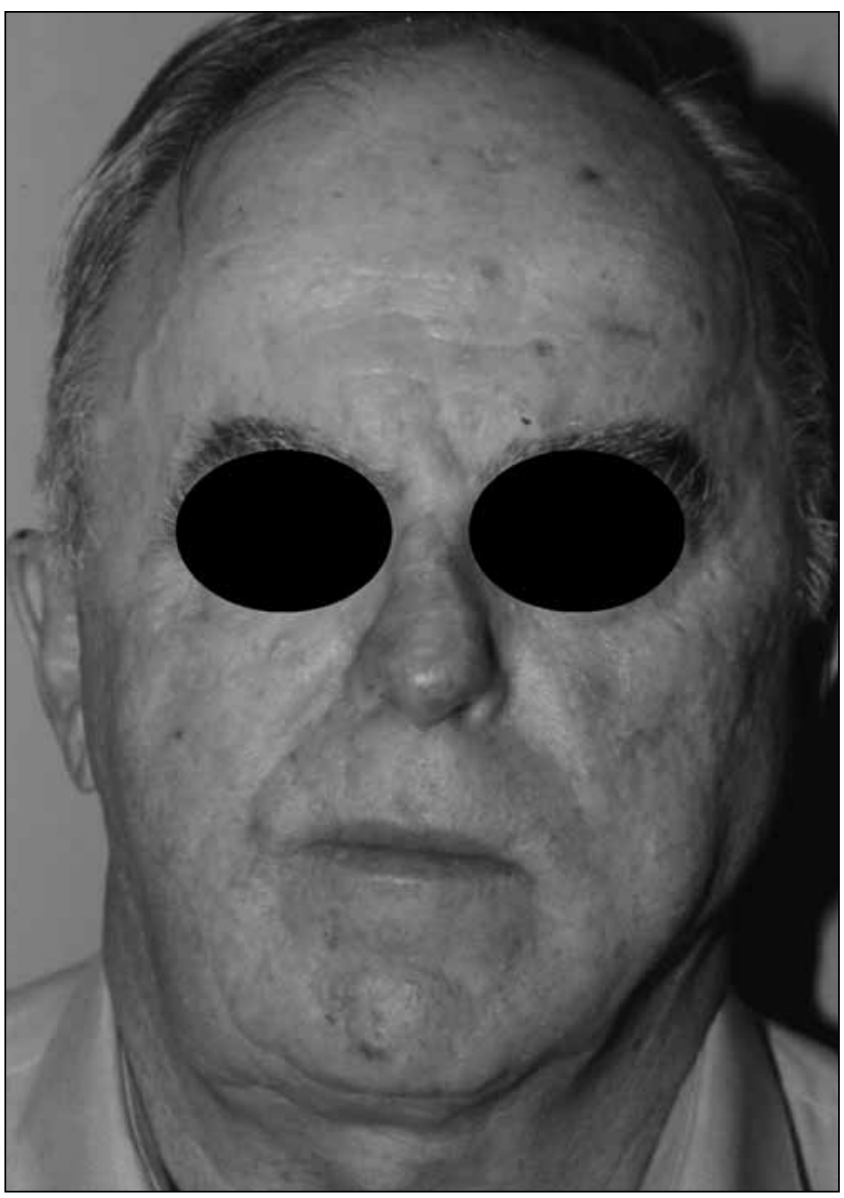

Figure 1) Gorlin's syndrome facies

of the falx cerebri, pitting of the palmar and plantar surfaces, and rib anomalies $(2,3)$.

Generally, in these patients the head appears large due to an increased size of the calvaria secondary to frontal and biparietal bossing (4). Due to the presence of a broad nasal root, there may be an appearance of hypertelorism. In $50 \%$ to $60 \%$ of people with this syndrome, facial milia are present, concentrated around the eyes, nose and upper lip. Cleft palate and/or lip are present in approximately $5 \%$ of this population (4).

The BCCs number in the tens to the thousands, and tend to first develop between puberty and 35 years of age. However, it has been shown that these lesions may be present in only $50 \%$ of patients (5). The lesions themselves are indiscernable from nonsyndromic BCC; typically reddish brown, papular and variously sized (Figure 2 ). The majority of BCC are of the nodular type (50\% to $70 \%$ ), followed by the superficial ( $9 \%$ to $10 \%$ ) and morpheaform types (1\% to $2 \%)$. They typically occur on the face, upper trunk and neck, and rarely on the abdomen, lower trunk and extremities (Figure 3). As for isolated BCCs, they are rarely aggressive and if so, only locally invasive.

Jaw cysts, otherwise known as odontogenic keratocysts, are seen in $75 \%$ to $85 \%$ of patients with Gorlin's syndrome (1). Contrary to the more common isolated odontogenic keratocyst, they typically develop earlier. Specifically, they develop in the first decade of life and increase in incidence until the second or third decades. They are usually discovered through routine dental checkups, because approximately one-third of

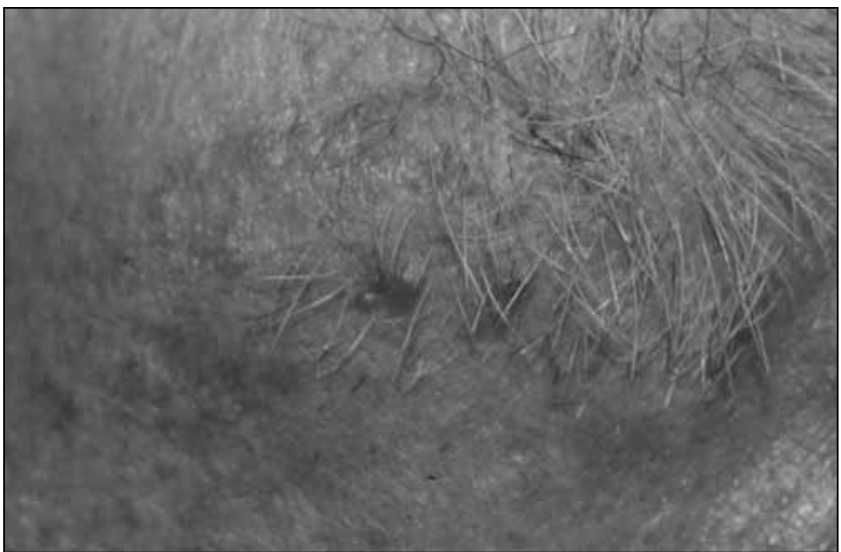

Figure 2) Basal cell carcinoma

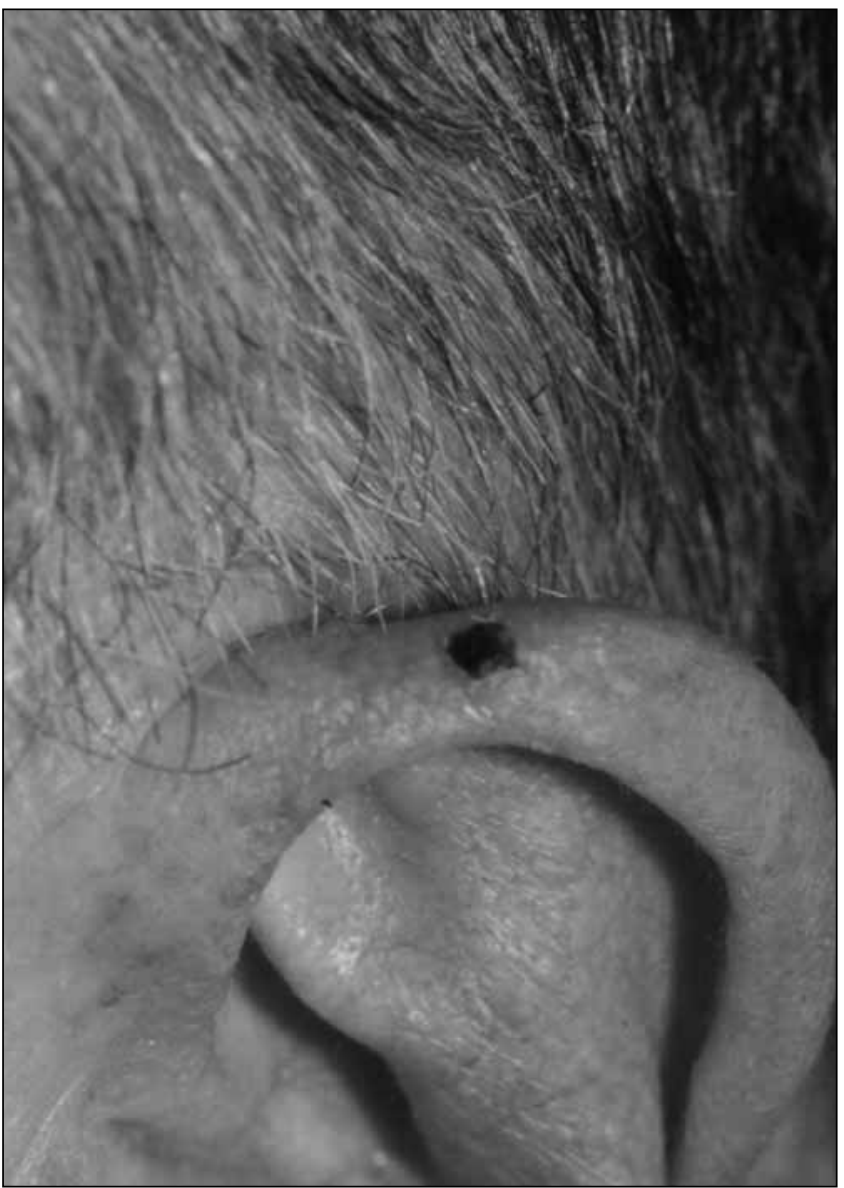

Figure 3) Pigmented basal cell carcinoma

patients are completely asymptomatic. However, many may eventually present with jaw swelling, dull pain and tooth displacement due to ongoing cyst growth (2). They are often large, multiple and bilateral and primarily involve the mandible but can present within the upper jaw. It is not uncommon (30\% to $60 \%$ ) for cysts to recur following surgical excision. This may be due to retention of epithelium, the presence of satellite microcysts or basal cell proliferation of 


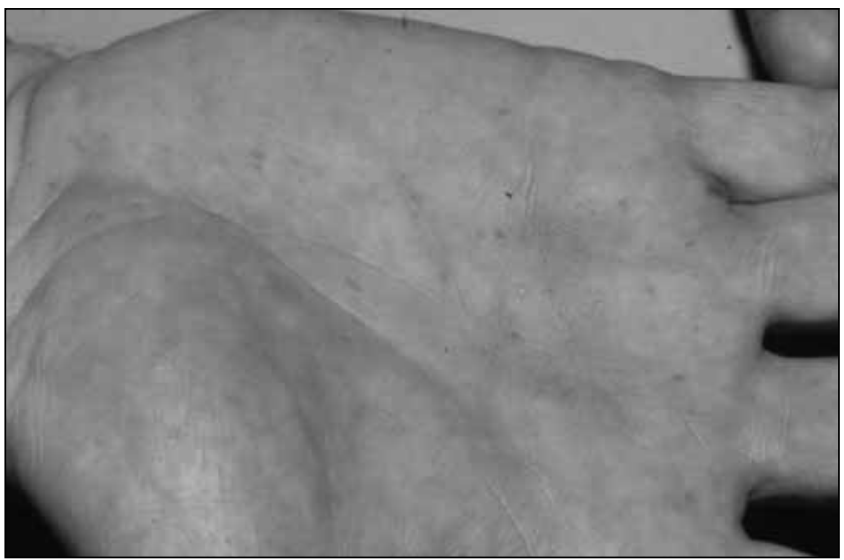

Figure 4) Palmar pitting

the epithelium (2). As well, they have the potential, although rare, to give rise to ameloblastoma and squamous cell carcinoma.

Small palmar and plantar pits are extremely common in this patient population ( $50 \%$ to $75 \%$ ) and are so uncommon outside this syndrome that they are virtually pathognomonic if present (Figure 4). They rarely occur on the dorsal surfaces of the finger or toes and occur more frequently on the hands rather than the feet. They are uncommon in children and, therefore, may be age-related. Occasionally, BCCs have been known to arise from the base of these pits, necessitating careful periodic examination of these patients (2). Visualization may be enhanced by soaking the patient's hands in warm water for 10 min before examination.

Musculoskeletal abnormalities are common among patients with Gorlin's syndrome. Rib anomalies occur in approximately $60 \%$ of cases; the ribs may be missing, bifid, anteriorly splayed, fused, hypoplastic or cervical in nature. Calcification of the

\section{REFERENCES}

1. Crean SJ, Cunningham SJ. Gorlin's syndrome: Main features and recent advances. Brit J Hosp Med 1996;56:392-7.

2. Gorlin RJ. Nevoid basal cell carcinoma syndrome. Dermatol Clin 1995;13:113-25.

3. Zarem HA, Lowe NJ. Benign growths and generalized skin disorders. In: Aston SJ, Beasley RW, Thorne CHM, eds. Grabb and Smith Plastic Surgery 5th edn. Philadelphia: Lippincott and Raven, 1997:113-6.

4. Gorlin RJ. Nevoid basal-cell carcinoma syndrome. Medicine 1987;66:98-113. falx cerebri is seen in up to $85 \%$ of patients with Gorlin's syndrome versus only $5 \%$ in the normal population. Other bony abnormalities include kyphoscoliosis (30\% to 40\%), polydactyly, syndactyly of the index and long fingers and shortening of fourth metacarpals (4). Pseudocystic lytic bone lesions have been identified in $35 \%$ to $45 \%$ of patients, involving the phalanges, metapodial bones, long bones, carpal and tarsal bones, and calvaria. These hamartomatous lesions consist of nerves, blood vessels and fibrous connective tissue (2).

Other syndromes that present with multiple BCC include Bazex syndrome, xeroderma pigmentosum and Rombo syndrome. A diagnosis of Gorlin's syndrome is achieved through a careful history and physical examination, along with obtaining skin lesion biopsies confirming the diagnosis of BCC. A panorex of the mandible should also be performed to rule out odontogenic cysts. All other studies are done as required.

Management of Gorlin's syndrome includes regular follow-up visits every two to three months for a complete skin exam (1). After the age of eight years, a panorex of the jaw should be performed once a year to monitor for jaw cysts which, if present, require complete surgical excision. For infants at risk, specifically those with a positive family history of Gorlin's syndrome, an annual magnetic resonance imaging of the head is recommended up to the age of eight years due to the higher incidence of medulloblastoma associated with this disease. It is possible for families to undergo molecular genetic linkage to identify the associated anomaly on chromosome 9. Susequent prenatal counselling should be encouraged.

When excessive numbers of BCCs are present, removal by invasive means becomes impractical. An alternative medical approach is the use of topical 5-flourouracil and $0.1 \%$ isotretinoin cream (6). Oral retinoids have been used with some success, but carry a $1 \%$ to $2 \%$ risk of hepatotoxity. Relatively newer approaches involve the use of imiquimod, intralesional application of interferon-alpha2b and photodynamic therapy (7). More invasive techniques include cryotherapy, curettage with electrodessication, carbon dioxide laser vaporization and finally, surgical excision (5).

5. Grobbelaar AO, Horlock N, Gault DT. Gorlin's syndrome: The role of the carbon dioxide laser in patient management. Ann Plast Surg 1997;39:366-73.

6. Strange PR, Lang PG. Long-term management of basal cell nevus syndrome with topical tretinoin and 5-flurouracil. J Am Acad Dermatol 1992;27:842-5.

7. Kopera D, Cerroni L, Fink-Puches R, Kerl H. Different treatment modalities for the management of a patient with the nevoid basal cell carcinoma syndrome. J Am Acad Dermatol 1996;34:937-9 